\title{
Microbubble assisted polyhydroxybutyrate production in Escherichia coli
}

Kadriye Inan ${ }^{1 \dagger}$, Fulya Ay Sal ${ }^{2 \dagger}$, Asif Rahman ${ }^{3,4 \dagger}$, Ryan J. Putmann ${ }^{5}$, Foster A. Agblevor ${ }^{5}$ and Charles D. Miller ${ }^{{ }^{*}}$

\begin{abstract}
Background: One of the potential limitations of large scale aerobic Escherichia coli fermentation is the need for increased dissolved oxygen for culture growth and bioproduct generation. As culture density increases the poor solubility of oxygen in water becomes one of the limiting factors for cell growth and product formation. A potential solution is to use a microbubble dispersion (MBD) generating device to reduce the diameter and increase the surface area of sparged bubbles in the fermentor. In this study, a recombinant E. coli strain was used to produce polyhydroxybutyrate (PHB) under conventional and MBD aerobic fermentation conditions.

Results: In conventional fermentation operating at $350 \mathrm{rpm}$ and $0.8 \mathrm{vvm}$ air flow rate, an $\mathrm{OD}_{600}$ of 6.21 and $\mathrm{PHB}$ yield of $23 \%$ (dry cell basis) was achieved. MBD fermentation with similar bioreactor operating parameters produced an $\mathrm{OD}_{600}$ of 8.17 and $\mathrm{PHB}$ yield of $43 \% \mathrm{PHB}$, which was nearly double that of the conventional fermentation.
\end{abstract}

Conclusions: This study demonstrated that using a MBD generator can increase oxygen mass transfer into the aqueous phase, increasing E. coli growth and bioproduct generation.

Keywords: Microbubble, Fermentation, Dissolved oxygen, Polyhydroxybutyrate, PHB

\section{Background}

Continued use of petroleum based plastics is not sustainable, therefore alternative and environmentally friendly materials need to be developed. Biologically derived polymers could potentially be a candidate to replace petroleum based plastics in the near future [1]. Currently bioplastics make up only $1 \%$ of the market share of all plastics used worldwide, in part due to various bottlenecks to making biological plastics economical on a large scale [2].

Polyhydroxyalkanoates (PHAs) are a class of biologically derived biopolymers with over 155 unique monomers [3]. The advantage of having many different monomers is that each possess different material

\footnotetext{
*Correspondence: charles.miller@usu.edu

${ }^{\dagger}$ Kadriye Inan, Fulya Ay Sal and Asif Rahman contributed equally to this work

${ }^{5}$ Department of Biological Engineering, Utah State University, 4105 Old Main Hill, Logan, UT 84322-4105, USA

Full list of author information is available at the end of the article
}

characteristics and thus will be suitable for many potential applications [4]. One such PHA polymer is polyhydroxybutyrate (PHB), a short chain length (scl) polymer, which has a melting point and tensile strength similar to polypropylene and a Young's modulus comparable to polystyrene [5]. PHB is naturally produced in organisms such as Ralstonia eutropha, Alcaligenes latus, Burkholderia cepacia, and Bacillus sphaericus [6-9]. The three genes responsible for $\mathrm{PHB}$ production $p h b \mathrm{~A}, p h b \mathrm{~B}$, $p h b \mathrm{C}$, can be recombinantly expressed in laboratory strains of Escherichia coli [10].

Large scale aerobic production of PHB can be carried out using genetically engineered $E$. coli strains in bioreactors [11]. The advantages of using recombinant $E$. coli for the production of PHB include rapid growth, accumulation of PHB greater than $50 \%$ of cell weight [12], and the ability to utilize inexpensive carbon substrates $[13,14]$.

Previous studies have demonstrated that PHB production using recombinant systems such as $E$. coli have been hindered upon scaling up in part due to the use of large 
amounts of oxygen required for high bacterial growth and PHB generation. The amount of required oxygen supplied through increased agitation or supplemental oxygen fed into a traditional bioreactor are potentially cost prohibitive for PHB production upon scale-up [15-19]. One of the major challenges in many aerobic bioreactor setups is the poor solubility of oxygen in the media. The solubility of oxygen in water is approximately $0.217 \mathrm{mmol} / \mathrm{l}$ at $35^{\circ} \mathrm{C}$, and with the addition of salts and other media components the solubility is further reduced [20]. Additionally, high cell density cultures (HCDC) could also reduce the available dissolved oxygen in a culture at high OD's [21].

A possible lower cost solution is to increase the relative surface area of air bubbles sparged into fermentor media. By reducing the bubble size, the oxygen transfer rate of the fermentor can be increased due to greater surface area. Furthermore, the velocity of the bubbles traveling from the bottom of a fermentor to the top is reduced, giving more time for oxygen transfer to the culture media. A microbubble dispersion (MBD) generator can reduce the size of a conventional sparged gas bubble from 3-5 mm to approximately $20-100 \mu \mathrm{m}[20,22]$. Additionally, it has been suggested that microbubble sparged fermentors can be energy efficient up to $0.01 \mathrm{~kW} / \mathrm{m}^{3}$ of fermentation capacity, providing lower overall operating costs [23].

Previous studies have utilized a MBD device in-line with a fermentor for recombinant product formation in Pichia pastoris, Saccharomyces cerevisiae, and Trichoderma reesei $[20,24,25]$. In the $P$. pastoris study, increase in cell growth and recombinant protein production were observed in the MBD system when compared to a standard sparged fermentation [24]. Trichoderma reesei was grown in a MBD system and demonstrated increase in cell mass [25]. Additionally, another study used a MBD system in-line with a $72 \mathrm{~L}$ fermentation vessel, demonstrating the versatile nature of the system for scale-up [26].

In this study, the objectives were to (1) demonstrate increased $E$. coli growth with a MBD system and (2) show increased PHB production from E. coli when MBD device was used compared to conventional air-sparged fermentation.

\section{Methods}

\section{Strain selection}

E. coli strain XL1-Blue (recA1 endA1 gyrA96 thi-1 hsdR17 supE44 relA1 lac [ $F^{\prime}$ proAB lacIqZAM15 Tn10 (TetR)]) (Agilent Technologies, Santa Clara, CA) harboring the ampicillin resistant plasmid pBHR68 was used in all studies [10]. The XL1-Blue strain of E. coli was chosen for its ability to out-perform other $E$. coli strains for PHB production [27]. The plasmid pBHR68 was selected as it contained the lactose inducible phaCAB operon and had demonstrated PHB accumulation up to approximately $50 \%$ of the dry cell weight after $48 \mathrm{~h}$ of growth in a minimal media [28].

\section{Culture media}

For all experiments single colonies were picked from Luria-Bertani (LB) agar plates, inoculated in $5 \mathrm{~mL}$ LB media pre-cultures and grown overnight at $37{ }^{\circ} \mathrm{C}$ [29]. These $5 \mathrm{~mL}$ cultures were then used to start larger $50 \mathrm{~mL}$ cultures. Larger cultures consisted of a modified M9 minimal media containing: M9 salts $\left(\mathrm{Na}_{2} \mathrm{HPO}_{4}\right.$, $\mathrm{KH}_{2} \mathrm{PO}_{4}, \mathrm{NaCl}, \mathrm{NH}_{4} \mathrm{Cl}$, Becton, Dickinson and Co, Sparks, MD), supplemented with $1.75 \%(w / v)$ glucose (ACS grade, Acros Organics, Fair Lawn, NJ), $0.2 \%$ (w/v) yeast extract (Becton, Dickinson and Co, Sparks, MD), and $100 \mu \mathrm{g} / \mathrm{ml}$ ampicillin (IBI Scientific, Peosta, IA). The addition of small amounts of yeast extract to the culture has been shown to increase PHB yields $[27,30]$. The $50 \mathrm{~mL}$ culture was grown overnight in an orbital shaker table at $37^{\circ} \mathrm{C}$ and $220 \mathrm{rpm}$ and was used to seed $1 \mathrm{~L}$ fermentors of the same media composition. For PHB production studies using fermentors, $0.1 \mathrm{mM}$ Isopropyl $\beta$-D-1-thiogalactopyranoside (IPTG) (Gold Biotechnology, Inc. St. Louis, MO) was added at the start of the fermentation $(\mathrm{t}=0 \mathrm{~h})$.

\section{Conventional air-sparged fermentation}

BIOSTAT Q multi-fermentor bioreactor system (B. Braun Biotech International, Melsungen, Germany) was used with a $1 \mathrm{~L}$ working volume similar to that used in a previous study [31]. Conventional air-sparged culturing was conducted for the production of PHB at agitation rates of 350,500 , or $750 \mathrm{rpm}$ with air-sparge rates of 0.4 or $0.8 \mathrm{vvm}$. The bioreactor was equipped with $\mathrm{pH}$, dissolved oxygen (DO), and temperature probes. Both the $\mathrm{DO}$ and $\mathrm{pH}$ probes were calibrated after sterilization. The DO and $\mathrm{pH}$ of the media were not controlled but allowed to fall freely during fermentation. Turbidity $\left(\mathrm{OD}_{600}\right)$ and glucose consumption were measured at $0,4,8,12,24$, and $48 \mathrm{~h}$. PHB production was measured at 12, 24, and $48 \mathrm{~h}$. All experiments were duplicated.

\section{Microbubble dispersion sparged fermentation}

A MBD generator was setup in-line with a 1 L BIOSTAT bioreactor running in batch-mode similar to that seen in a previous study [31]. In addition to bioreactor setup mentioned in the previous section, the MBD generator, containing a stainless steel disc $5 \mathrm{~cm}$ in diameter and $3 \mathrm{~mm}$ thick, was connected to a high-speed electrical motor that spun the disk at approximately $4000 \mathrm{rpm}$. Baffles $5 \mathrm{~mm}$ from the spinning disk generated a high sheared zone and air was fed into the MBD generator at $0.8 \mathrm{vvm}$ to create microbubbles. Microbubbles were fed 
into the bioreactor using a peristaltic pump and Masterflex ${ }^{\circledR}$ tubing at approximately $100-150 \mathrm{ml} / \mathrm{min}$. A second peristaltic pump was used to pump fluid back to the MBD generator from the bioreactor at a similar flowrate to maintain a constant bioreactor volume. The recycling of the fermentation broth also served as a microbubble stabilizer because the natural surfactants generated by the $E$. coli assisted in stabilizing the microbubbles. As with the conventional air-sparged bioreactor, DO and $\mathrm{pH}$ were not controlled but allowed to fall freely. The media used in the MBD study was the same as that used in the air-sparge fermentation studies and no additional surfactants were used to stabilize the microbubbles generated. Turbidity $\left(\mathrm{OD}_{600}\right)$, glucose consumption, and PHB production was measured at the same time points as conventional air-sparged fermentation experiments. Bioreactor impeller speed of $350 \mathrm{rpm}$ was maintained over the course of the MBD study. All experiments were duplicated.

\section{Glucose analysis}

Glucose concentration was determined with a glucose assay reagent kit (Sigma Aldrich, St Louis, MO) using a modified procedure similar to a previous study [13]. Briefly, $120 \mu \mathrm{l}$ glucose assay reagent was added to $60 \mu \mathrm{l}$ sample and incubated at $37{ }^{\circ} \mathrm{C}$ for $30 \mathrm{~min}$. After incubation, $120 \mu \mathrm{l}$ of $12 \mathrm{~N} \mathrm{H}_{2} \mathrm{SO}_{4}$ was added to stop the enzymatic reaction. Absorbance was measured at $540 \mathrm{~nm}$ using a Synergy 2 microtiter plate reader (BioTek, Winooski, VT). Concentration calculations were carried out according to a glucose standard curve.

\section{PHB concentration determination}

PHB concentration was determined by an NMR-GC correlation [32] at 12, 24, and $48 \mathrm{~h}$ respectively. The methods used in this study followed a procedure developed previously [32]. After fermentation approximately $100 \mathrm{~mL}$ of culture was centrifuged, frozen to $-80{ }^{\circ} \mathrm{C}$, and lyophilized. $15 \mathrm{mg}$ of lyophilized sample was mixed with equal volumes of $5 \%$ sodium hypochlorite and deuterated chloroform containing $0.03 \%$ TMS (Cambridge Isotope Laboratories, Inc. Andover, MA). Samples were centrifuged to promote phase separation and the organic phase was analyzed using ${ }^{1} \mathrm{H}$ NMR (Jeol ECX-300 NMR, Jeol USA, Inc. Peabody, MA). PHB concentration was determined from an NMR-GC calibration standard [32].

\section{Calculation of oxygen transfer coefficient}

The volumetric oxygen transfer coefficient $\left(k_{L} a\right)$ was determined using a non-fermentative method ("gas outgas in") as discussed by Tribe et al. [33]. The advantage of this technique is that $\mathrm{k}_{\mathrm{L}}$ a can be determined directly from dissolved oxygen (DO) measurement [34]. Briefly, this method requires gassing the bioreactor with nitrogen to displace the dissolved $\mathrm{O}_{2}$. Next, air was gassed into the system at sparging rate of $0.4,0.8 \mathrm{vvm}$, or via MBD. DO \% was recorded over time until DO \% reached approximately 90-95\%. Equation 1 [33] can be used for determining $\mathrm{k}_{\mathrm{L}} \mathrm{a}$, where: $\mathrm{dC}_{\mathrm{L}} / \mathrm{dt}$ is change in $\mathrm{DO}$ over time $(\mathrm{t}), \mathrm{C}^{*}$ is saturated $\mathrm{DO}$ concentration, and $\mathrm{C}_{\mathrm{L}}$ is $\mathrm{DO}$ concentration in the bioreactor.

$$
\mathrm{dC}_{\mathrm{L}} / \mathrm{dt}=\mathrm{k}_{\mathrm{L}} \mathrm{a}\left(\mathrm{C}^{*}-\mathrm{C}_{\mathrm{L}}\right)
$$

Integrating Eq. 1 and solving for $\mathrm{k}_{\mathrm{L}}$ a gives Eq. 2.

$$
\mathrm{k}_{\mathrm{L}} \mathrm{a}=\ln \left(\mathrm{C}^{*}-\mathrm{C}_{\mathrm{L}}\right) / \mathrm{t}
$$

Plotting $\ln \left(C^{*}-C_{L}\right)$ verses time $(t)$ produces a linear graph with a slope equal to the $\mathrm{k}_{\mathrm{L}}$ a in reciprocal time $\left(h^{-1}\right)$.

\section{Results and discussion}

\section{E. coli growth using a MBD}

The growth of XL1-Blue E. coli harboring the plasmid pBHR68 was found to be highest $\left(\mathrm{OD}_{600}\right.$ approximately 13.86) in the bioreactor agitated at $750 \mathrm{rpm}$ with an airflow of $0.8 \mathrm{vvm}$ after $48 \mathrm{~h}$ post inoculation as shown in Fig. 1. The lowest growth was measured in the bioreactor operating at $350 \mathrm{rpm}$ at $0.4 \mathrm{vvm}$ yielding an average $\mathrm{OD}_{600}$ of 3.66. It was expected that the lowest agitation and air sparging rates would give the lowest overall growth due to oxygen limitations in the media. When the MBD generator was used, the average $\mathrm{OD}_{600}$ of the culture was 8.17 at $48 \mathrm{~h}$ compared to 6.21 obtained for similar fermentation without MBD at $48 \mathrm{~h}$ post inoculation. This suggests that the presence of MBD aided in the growth of E. coli by increasing the amount of oxygen uptake by the bacteria.

It was observed that the faster the agitation speed (rpm), the shorter the time to reach saturated levels of DO concentration and thus the higher the volumetric oxygen transfer coefficient $\left(\mathrm{k}_{\mathrm{L}} \mathrm{a}\right)$. The $\mathrm{k}_{\mathrm{L}} \mathrm{a}$ for conventional air sparged and MBD systems are shown in Table 1 . The $\mathrm{k}_{\mathrm{L}}$ a value increased from 16.81 to $23.47 \mathrm{~h}^{-1}$ for 0.4 vvm when the agitation rate was increased from 350 to $500 \mathrm{rpm}$. At $500 \mathrm{rpm}$ doubling the aeration rate to 0.8 vvm showed only a slight improvement in $\mathrm{k}_{\mathrm{L}} \mathrm{a}\left(27.53 \mathrm{~h}^{-1}\right)$. At a higher agitation rate of $750 \mathrm{rpm}$ with conventional air-sparging at $0.4 \mathrm{vvm}$ the $\mathrm{k}_{\mathrm{L}}$ a achieved was $32.86 \mathrm{~h}^{-1}$. For the MBD system with a bioreactor operating at $350 \mathrm{rpm}$ a $\mathrm{k}_{\mathrm{L}}$ a of $23.12 \mathrm{~h}^{-1}$ was observed, higher than the $\mathrm{k}_{\mathrm{L}}$ a of $22.01 \mathrm{~h}^{-1}$ observed in the bioreactor operating under similar conditions ( $350 \mathrm{rpm}, 0.8 \mathrm{vvm}$ ). The $\mathrm{k}_{\mathrm{L}} \mathrm{a}$ present in the MBD system was lower than the $\mathrm{k}_{\mathrm{L}} \mathrm{a}$ in the $750 \mathrm{rpm}$ systems but similar to the $\mathrm{k}_{\mathrm{L}} \mathrm{a}$ in the $500 \mathrm{rpm}$ air sparged studies, suggesting similar performance of the MBD system with the $500 \mathrm{rpm}$ systems. 


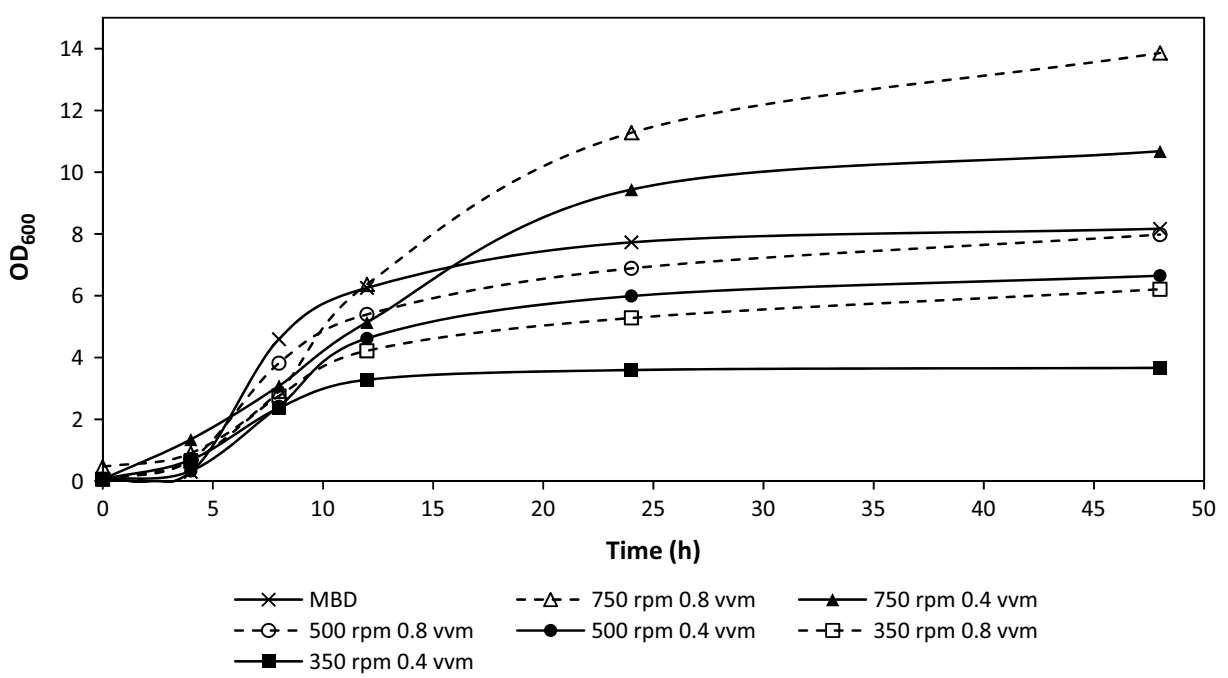

Fig. 1 Growth profiles $\left(\mathrm{OD}_{600}\right)$ for recombinant E. coli harboring the pBHR68 plasmid grown in conventional and MBD sparged fermentations at different agitation rates $(n=2)$

Table 1 Oxygen transfer coefficient $k_{\mathrm{L}} a\left(\mathrm{~h}^{-1}\right)$ value for fermentations with conventional air sparged and MBD sparged fermentations $(n=2)$

\begin{tabular}{|c|c|c|c|c|c|c|c|}
\hline Air supply & Air-sparger & Air-sparger & Air-sparger & Air-sparger & Air-sparger & Air-sparger & MBD \\
\hline Agitation rate (rpm) & 350 & 350 & 500 & 500 & 750 & 750 & 350 \\
\hline Air sparge rate (vvm) & 0.4 & 0.8 & 0.4 & 0.8 & 0.4 & 0.8 & - \\
\hline $\mathrm{k}_{\mathrm{L}} \mathrm{a}\left(\mathrm{h}^{-1}\right)$ & 16.81 & 22.01 & 23.47 & 27.53 & 32.86 & 34.29 & 23.12 \\
\hline $\mathrm{OD}_{600}(48 \mathrm{~h})$ & 3.66 & 6.21 & 5.99 & 7.98 & 10.68 & 13.86 & 8.17 \\
\hline PHB \% (48 h) & 20.25 & 23.93 & 26.12 & 46.46 & 47.33 & 54.08 & 43.14 \\
\hline
\end{tabular}

As expected, glucose concentrations in the media decreased over the course of the $48 \mathrm{~h}$ study for all bioreactor conditions. Glucose was completely exhausted after approximately $24 \mathrm{~h}$ in bioreactor studies with an agitation rate of $750 \mathrm{rpm}$ and sparging rate of 0.4 and 0.8 vvm. After $48 \mathrm{~h}$ glucose present in the MBD and $500 \mathrm{rpm}$ $0.8 \mathrm{vvm}$ studies approached $0 \mathrm{mg} / \mathrm{L}$ (Fig. 2). Since the initial measured concentration of glucose in all studies was approximately $1.75 \%(\mathrm{w} / \mathrm{v})$, coupling these findings with the $\mathrm{k}_{\mathrm{L}} \mathrm{a}$ and $\mathrm{OD}_{600}$ results demonstrates that this system is oxygen limited.

Dry cell weight $(\mathrm{dcw})$ correlated with $E$. coli growth measured with $\mathrm{OD}_{600}$. The most turbid culture $(750 \mathrm{rpm}$, $0.8 \mathrm{vvm}$ ) also showed the highest dry cell weight after $48 \mathrm{~h}$ of culturing producing on average $4.57 \mathrm{~g} / \mathrm{L}$ of dry biomass equivalent (Fig. 3). After $48 \mathrm{~h}$ the MBD system generated approximately $2.49 \mathrm{~g} / \mathrm{L}$ dry cell weight, which was similar to the sparged system operating at $500 \mathrm{rpm}$ and $0.8 \mathrm{vvm}$ and higher than the sparged system operating at $350 \mathrm{rpm}$. The difference in dry cell weight between the bioreactor conditions can be attributed to the lack of DO present in the media. The theoretical amount of oxygen required for $E$. coli growing on glucose based media is approximately $1 \mathrm{~g}$ of oxygen for $1 \mathrm{~g}$ of $E$. coli biomass [35]. In this study the starting concentration of glucose was the same, yet in only two instances was the glucose completely exhausted, thus suggesting lack of usable oxygen in the system.

\section{PHB production analysis}

All cultures showed increase in PHB accumulation through 12, 24, and $48 \mathrm{~h}$ respectively (Fig. 4). Although, as illustrated in Fig. 1, stationary phase was reached between 12 and $24 \mathrm{~h}$ for most experiments, bioreactors were run for $48 \mathrm{~h}$ as this allowed for accumulation of PHB. Previous studies have mentioned that PHB does not accumulate to significantly high levels during log phase of growth. Rather, acetyl-CoA is used for cell growth during exponential phase and then utilized for PHB production during the stationary phase, thus the motivation to culture for $48 \mathrm{~h}$ [36].

After $48 \mathrm{~h}$ of culturing, the average PHB \% accumulation for conventional air-sparged experiments $(0.4 \mathrm{vvm})$ at agitation rates of 350,500 , and $750 \mathrm{rpm}$, were 20.25 , 


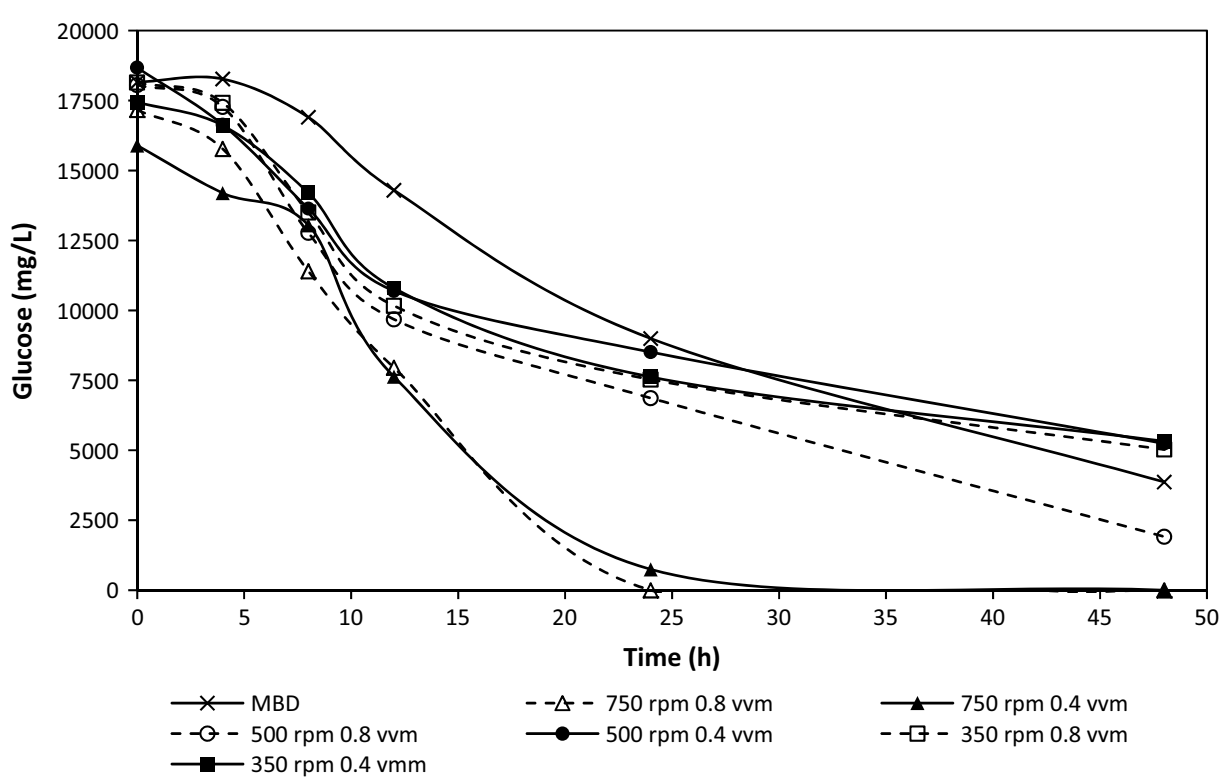

Fig. 2 Glucose consumption (mg/L) over time (h) for PHB producing E.coli in conventional and MBD sparged fermentations at different agitation rates $(n=2)$

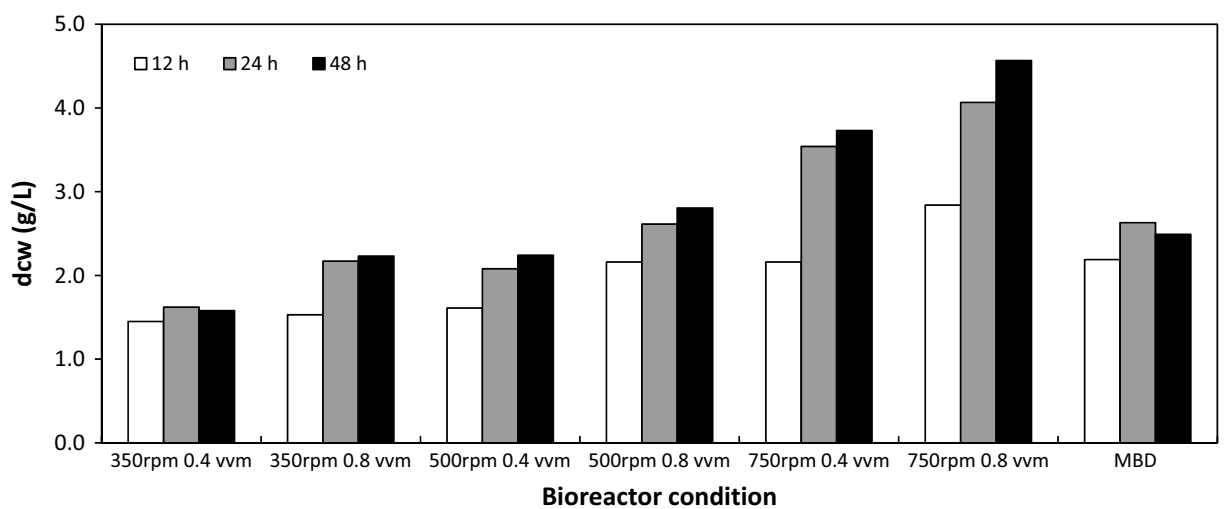

Fig. 3 Dry cell weight ( $\mathrm{g} / \mathrm{L}$ ) of recombinant E. coli harboring the pBHR68 plasmid grown in conventional and MBD sparged fermentations measured at 12,24 , and $48 \mathrm{~h}(\mathrm{n}=2)$

26.12, and $47.33 \%$, respectively. At the same agitation rates with an increased air flow to $0.8 \mathrm{vvm}$ the PHB \% after $48 \mathrm{~h}$ was increased to $23.93,46.46$, and $54.08 \%$, respectively. For the $350 \mathrm{rpm}$ bioreactor studies the difference between air sparged at 0.4 and $0.8 \mathrm{vvm}$ did not provide a substantial increase in PHB production, whereas doubling the air flow rate for the 500 and $750 \mathrm{rpm}$ agitation increased the PHB production significantly. The MBD bioreactor had an average PHB accumulation of $43.14 \% 48 \mathrm{~h}$ post inoculation, which was similar to the $500 \mathrm{rpm}$ agitation rate with $0.8 \mathrm{vvm}$ air sparging and also outperformed the $350 \mathrm{rpm} 0.8 \mathrm{vvm}$ study. Accumulation of PHB to approximately $40-50 \%$ after $48 \mathrm{~h}$ of culturing is similar to the results observed in shaker flask experiments in other studies with similar media composition and without $\mathrm{pH}$ or DO control $[28,30]$.

As discussed previously, oxygen limitations hindered both cell growth and PHB yields. This observation was also seen in prior studies, where oxygen limited fermentation experiments revealed reduced cell growth and lower PHB yields [37, 38]. Additionally, reduction in available oxygen could significantly affect native metabolic pathways in E. coli, including ATP generation, further limiting bacterial growth and hindering bioproduct generation [16]. In this study, the higher rpm experiments and MBD produced increased levels of PHB production compared 


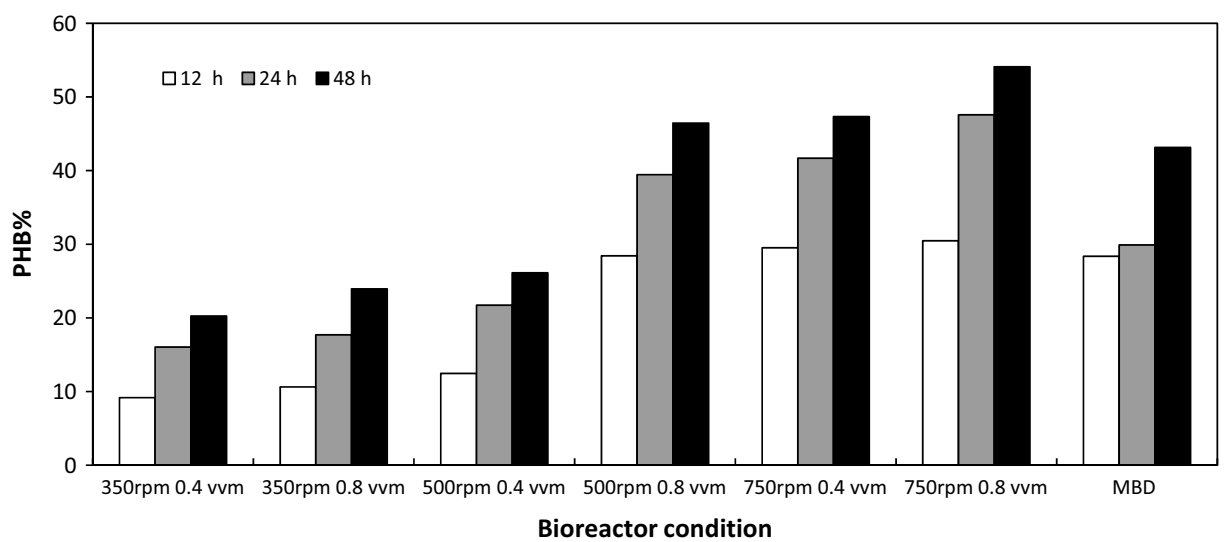

Fig. 4 PHB production (\% of dry cell weight) from recombinant E. coli grown in conventional and MBD sparged fermentations measured at 12, 24, and $48 \mathrm{~h}(\mathrm{n}=2)$

to lower speed air-sparged fermentations, suggesting that oxygen limitations hindered cell growth and PHB generation.

Other fermentation based studies have used similar strains of XL1-Blue E. coli to produce PHB. One such study optimized media contents, maintained $\mathrm{pH}$, used pure oxygen, and increased agitation speeds up to $1100 \mathrm{rpm}$. While this study produced high yields of PHB, the authors concluded that the scale-up of this system would not be cost effective due to considerable costs of using pure oxygen [27]. Combining a MBD approach with an optimized media used in the aforementioned study could potentially reduce the costs of bacterial fermentation to produce PHBs.

The results presented in this study provide justification for future work using the MBD generator in-line with a larger bioreactor for E. coli growth and PHB production. It has been reported that the power input per unit volume is approximately 1000 times higher in a laboratory based fermentation unit when compared to an industrial scale unit [20]. Scale-up from 1 to $50 \mathrm{~L}$ for S. cerevisiae fermentations using a MBD unit have been proven to be successful with a threefold reduction in power consumption using a MBD unit as compared to conventional air sparging [26]. It would be reasonable to suggest that $E$. coli grown in a $50 \mathrm{~L}$ MBD fed fermentor would give similar results. The next step would be to understand how the MBD unit would function upon scale-up and if a larger MBD system would be required for a larger scale fermentor. Furthermore, another consideration upon scale-up would be if any additional surfactants would be required to maintain microbubble size and if these additional surfactants affected E.coli growth and PHB yield.

\section{Conclusions}

The production of PHB using genetically engineered $E$. coli requires a large oxygen supply that results in excessive energy consumption and therefore makes the process less economically competitive. The major challenge is the poor solubility of oxygen in the fermentation media because the amount of energy input required for agitation and aeration becomes exceedingly high. The use of a MBD generator can increase oxygen mass transfer into the aqueous phase, further promoting E. coli growth and bioproduct generation. The $\mathrm{DO}$ and $\mathrm{pH}$ of the media were not controlled in these experiments, though future work could consist of understanding the effects of controlling $\mathrm{DO}$ and $\mathrm{pH}$ on cell growth and $\mathrm{PHB}$ yield. Perhaps maintaining the $\mathrm{pH}$ at a stable level could have further increased the yield of PHB produced in system. Furthermore, developing an understanding how the MBD system would function in an industrial fed-batch environment could allow for this system be implemented in the future. Production of other recombinant products could also be tested using the methods outlined in this study.

\section{Authors' contributions}

$\mathrm{KI}, \mathrm{FAS}$, and AR conducted experiments and wrote the manuscript draft. FAA conceived and designed the experiments. RJP assisted with experiments and data analysis. CDM assisted with experimental design and manuscript revision. All authors read and approved the final manuscript.

\section{Author details}

${ }^{1}$ Department of Molecular Biology and Genetics, Karadeniz Technical University, Trabzon, Turkey. ${ }^{2}$ Department of Biology, Karadeniz Technical University, Trabzon, Turkey. ${ }^{3}$ Bioengineering Branch, Space Biosciences Division, NASA Ames Research Center, Moffett Field, Ames, CA 94035-1000, USA. ${ }^{4}$ Universities Space Research Association, Mountain View, CA 94043, USA. ${ }^{5}$ Department of Biological Engineering, Utah State University, 4105 Old Main Hill, Logan, UT 84322-4105, USA. 


\section{Acknowledgements}

The authors would also like to acknowledge Ashik Sathish, Bo Zhao, Brian Smith, and Jordan Morley for their assistance.

\section{Competing interests}

The authors declare that they have no competing interests.

\section{Availability of data and materials}

Data will be made available upon request from the corresponding author.

\section{Ethics approval and consent to participate}

Not applicable as study did not involve human subjects.

\section{Funding}

The authors would like to recognize the following groups for their funding and support: the Scientific and Technological Research Council of Turkey (TÜBITAK), the Turkey Council of Higher Education (YÖK), the Utah Science Technology and Research (USTAR) Program, and the Synthetic Biomanufacturing Institute (SBI).

Received: 5 April 2016 Accepted: 1 July 2016

Published online: 09 July 2016

\section{References}

1. Chanprateep S. Current trends in biodegradable polyhydroxyalkanoates. J Biosci Bioeng. 2010;110:621-32.

2. Sreedevi S, Unni K, Sajith S, Priji P, Josh M, Benjamin S. Bioplastics: advances in polyhydroxybutyrate research. Advances in polymer science. Berlin: Springer; 2015. p. 1-30.

3. Agnew DE, Pfleger BF. Synthetic biology strategies for synthesizing polyhydroxyalkanoates from unrelated carbon sources. Chem Eng Sci. 2013;103:58-67.

4. Rehm BHA. Bacterial polymers: biosynthesis, modifications and applications. Nat Rev Microbiol. 2010;8:578-92.

5. Khanna S, Srivastava AK. Recent advances in microbial polyhydroxyalkanoates. Process Biochem. 2005;40:607-19.

6. Ryu HW, Cho KS, Lee EG, Chang YK. Recovery of poly(3-hydroxybutyrate) from coagulated Ralstonia eutropha using a chemical digestion method. Biotechnol Prog. 2000;16:676-9.

7. Singhaboot P, Kaewkannetra P. A higher in value biopolymer product of polyhydroxyalkanoates (PHAs) synthesized by Alcaligenes latus in batch/ repeated batch fermentation processes of sugar cane juice. Ann Microbiol. 2015;65:2081-9.

8. Ramadas N, Sindhu R, Binod P, Pandey A. Development of a novel solidstate fermentation strategy for the production of poly-3-hydroxybutyrate using polyurethane foams by Bacillus sphaericus NII 0838. Ann Microbiol. 2013;63:1265-74

9. Dietrich D, IIIman B, Crooks C. Differential sensitivity of polyhydroxyalkanoate producing bacteria to fermentation inhibitors and comparison of polyhydroxybutyrate production from Burkholderia cepacia and Pseudomonas pseudoflava. BMC Research Notes. 2013;6:1-4.

10. Spiekermann P, Rehm BHA, Kalscheuer R, Baumeister D, Steinbüchel A. A sensitive, viable-colony staining method using Nile red for direct screening of bacteria that accumulate polyhydroxyalkanoic acids and other lipid storage compounds. Arch Microbiol. 1999;171:73-80.

11. lenczak JL, Schmidell W, De Aragão GMF. High-cell-density culture strategies for polyhydroxyalkanoate production: a review. J Ind Microbiol Biotechnol. 2013;40:275-86.

12. Wang F, Lee SY. High cell density culture of metabolically engineered Escherichia coli for the production of poly(3-hydroxybutyrate) in a defined medium. Biotechnol Bioeng. 1998;58:325-8.

13. Rahman A, Putman RJ, Inan K, Sal FA, Sathish A, Smith T, Nielsen C, Sims RC, Miller CD. Polyhydroxybutyrate production using a wastewater microalgae based media. Algal Res. 2015;8:95-8.

14. Rahman A, Anthony RJ, Sathish A, Sims RC, Miller CD. Effects of wastewater microalgae harvesting methods on polyhydroxybutyrate production. Bioresour Technol. 2014;156:364-7.
15. Choi Jl, Lee SY. Process analysis and economic evaluation for poly(3hydroxybutyrate) production by fermentation. Bioprocess Eng. 1997:17:335-42.

16. Lee SY, Choi J-i, Wong HH. Recent advances in polyhydroxyalkanoate production by bacterial fermentation: mini-review. Int J Biol Macromol. 1999;25:31-6.

17. Lee SY. High cell-density culture of Escherichia coli. Trends Biotechnol. 1996;14:98-105.

18. Choi J, Lee SY. Factors affecting the economics of polyhydroxyalkanoate production by bacterial fermentation. Appl Microbiol Biotechnol. 1999:51:13-21.

19. Van Wegen RJ, Ling Y, Middelberg APJ. Industrial production of polyhydroxyalkanoates using Escherichia Coli: an economic analysis. Chem Eng Res Des. 1998;76:417-26.

20. Kaster J, Michelsen D, Velander W. Increased oxygen transfer in a yeast fermentation using a microbubble dispersion. Appl Biochem Biotechnol. 1990;24-25:469-84

21. Choi JH, Keum KC, Lee SY. Production of recombinant proteins by high cell density culture of Escherichia coli. Chem Eng Sci. 2006;61:876-85.

22. Sebba F. An improved generator for micron-sized bubbles. Chem Ind $1985 ; 4: 91-2$

23. Bredwell MD, Worden RM. Mass-transfer properties of microbubbles. 1. experimental studies. Biotechnol Prog. 1998;14:31-8.

24. Zhang W, Li ZJ, Agblevor FA. Microbubble fermentation of recombinant Pichia pastoris for human serum albumin production. Process Biochem. 2005;40:2073-8.

25. Weber J, Agblevor FA. Microbubble fermentation of Trichoderma reesei for cellulase production. Process Biochem. 2005;40:669-76.

26. Hensirisak P, Parasukulsatid P, Agblevor FA, Cundiff JS, Velander WH. Scaleup of microbubble dispersion generator for aerobic fermentation. Appl Biochem Biotechnol. 2002;101:211-27.

27. Lee SY, Chang HN. Production of poly(3-hydroxybutyric acid) by recombinant Escherichia coli strains: genetic and fermentation studies. Can J Microbiol. 1995;41:207-15.

28. Rahman A, Linton E, Hatch AD, Sims RC, Miller CD. Secretion of polyhydroxybutyrate in Escherichia coli using a synthetic biological engineering approach. J Biol Eng. 2013;7:24.

29. Sambrook J, Russel DW. Molecular cloning: a laboratory manual. Cold Spring Harbor: Cold Spring Harbor Laboratory Press; 2001.

30. Kang Z, Wang Q, Zhang HJ, Qi QS. Construction of a stress-induced system in Escherichia coli for efficient polyhydroxyalkanoates production. Appl Microbiol Biotechnol. 2008;79:203-8.

31. Zhao B, Agblevor FA, Ritesh KC, Jelesko JG. Enhanced production of the alkaloid nicotine in hairy root cultures of Nicotiana tabacum L. Plant Cell, Tissue and Organ Culture (PCTOC). 2013;113:121-9.

32. Linton E, Rahman A, Viamajala S, Sims RC, Miller CD. Polyhydroxyalkanoate quantification in organic wastes and pure cultures using a single-step extraction and 1H NMR analysis. Water Sci Technol. 2012;66:1000-6.

33. Tribe LA, Briens CL, Margaritis A. Determination of the volumetric mass transfer coefficient ( $k$ La) using the dynamic "gas out-gas in" method: analysis of errors caused by dissolved oxygen probes. Biotechnol Bioeng. 1995:46:388-92.

34. Bandyopadhyay B, Humphrey AE, Taguchi H. Dynamic measurement of the volumetric oxygen transfer coefficient in fermentation systems. Biotechnol Bioeng. 1967;9:533-44.

35. Shiloach J, Fass R. Growing E. coli to high cell density-a historical perspective on method development. Biotechnol Adv. 2005;23:345-57.

36. Lee SY, Yim KS, Chang HN, Chang YK. Construction of plasmids, estimation of plasmid stability, and use of stable plasmids for the production of poly(3-hydroxybutyric acid) by recombinant Escherichia coli. J Biotechnol. 1994:32:203-11.

37. Wang FL, Lee SY. Production of poly(3-hydroxybutyrate) by fed-batch culture of filamentation-suppressed recombinant Escherichia coli. Appl Environ Microbiol. 1997;63:4765-9.

38. de Almeida A, Giordano AM, Nikel PI, Pettinari MJ. Effects of aeration on the synthesis of Poly(3-Hydroxybutyrate) from glycerol and glucose in recombinant Escherichia coli. Appl Environ Microbiol. 2010;76:2036-40. 